\title{
Clinical Determinants of Myocardial Injury, Detectable and Serial Troponin Levels among Patients with Hypertensive Crisis
}

Giancarlo Acosta ${ }^{1}$, Ahmed Amro ${ }^{1}$, Rodrigo Aguilar ${ }^{2}$, Waiel Abusnina ${ }^{1}$, Niharika Bhardwaj ${ }^{3}$, George Augustine Koromia ${ }^{1}$, Mark Studeny ${ }^{1}$, Affan Irfan ${ }^{1}$

1. Cardiology, Marshall University, Huntington, USA 2. Internal Medicine, Marshall University, Joan C. Edwards School of Medicine, Huntington, USA 3. Clinical and Translational Science, Marshall University, Joan C. Edwards School of Medicine, Huntington, USA

Corresponding author: Giancarlo Acosta, gacostamd@gmail.com

\section{Abstract \\ Introduction}

There is a high prevalence of hypertensive crisis with myocardial injury, as evidenced by elevation in cardiac troponin levels. The risk factors predisposing patients to developing a myocardial injury, detectable troponin, and increase in serial troponin in this population are not known.

\section{Methods}

A retrospective study was designed to include all patients, presenting to the emergency room, diagnosed with hypertensive crisis, using International Classification of Diseases, $10^{\text {th }}$ revision, Clinical Modification (ICD-10-CM) codes between 2016-2018 ( $\mathrm{n}=467)$. Logistic regression was used to determine the important predictors of myocardial injury evidenced by troponin elevation $>99^{\text {th }}$ percentile of upper reference level (URL), detectable troponin (>0.015 ng/ml), and increase in serial troponin levels.

\section{Results}

The $99^{\text {th }}$ percentile of the initial troponin level among all patients was $0.433 \mathrm{ng} / \mathrm{ml}$. A total of $15 \%$ had a myocardial injury, and the significant risk factors associated with it were body mass index (BMI) $<30 \mathrm{~kg} / \mathrm{m} 2$ (odds ratio [OR] 0.50, confidence interval [CI] 0.28-0.89), congestive heart failure (CHF; OR 4.28, CI 2.218.25 ) and prior use of aspirin (OR 1.98, CI 1.08-3.63). About 35\% had detectable troponin, and BMI < 30 $\mathrm{kg} / \mathrm{m}^{2}$ (OR 0.62, CI 0.40-0.97), CHF (OR 3.49, CI 2.06-5.9), elevated creatinine (OR 1.17, CI 1.02-1.34) and age <61 years (OR 0.59, CI 0.38-0.94) were associated with it. The factors associated with an increase in serial troponin were BMI < $30 \mathrm{Kg} / \mathrm{m} 2$ (OR 0.56, CI 0.36-0.87), CHF (OR 1.78, CI 1.06-3.0), coronary artery disease (CAD; OR 2.08, CI 1.28-3.36) and non-Caucasian race (OR 0.52, CI 0.29-0.93).

Received 01/11/2020

Review began 01/18/2020 Review ended 01/22/2020 Published 01/27/2020

() Copyright 2020

Acosta et al. This is an open access article distributed under the terms of the Creative Commons Attribution License CC-BY 3.0., which permits unrestricted use, distribution, and reproduction in any medium, provided the original author and source are credited.

\section{Conclusion}

About one-third of patients with the hypertensive crisis have detectable troponin. Still, among these, less than half have troponin levels $>99^{\text {th }}$ percentile URL, and the majority of these patients have minimal changes in serial troponin. Low BMI was associated with higher initial and serial troponin levels, and this obesity paradox was stronger among females and older patients.

Categories: Cardiology, Emergency Medicine, Internal Medicine

Keywords: hypertension, hypertensive crisis, troponin, myocardial injury, body mass index, obesity, hypertensive emergency, hypertensive urgency, myocardial infarction

\section{Introduction}

About one to two percent of patients with hypertension will develop hypertensive crisis in their lifetime [1]. It occurs when systolic blood pressure (SBP) is > 180 and/or diastolic blood pressure (DBP) $>120$, and is further classified into hypertensive emergency or urgency depending on the presence of end-organ damage. Hypertensive crisis is a serious condition with a one-year death rate of greater than $70 \%$ when left untreated [2]. One commonly affected tissue in extremely elevated blood pressure is the myocardium. Ischemic heart disease is usually precipitated by the increased myocardial oxygen demand, which can occur even in the absence of obstructive coronary artery disease (CAD) or acute atherosclerotic plaque rupture [1, 3, 4]. There is data suggesting that extreme elevations in blood pressure cause endothelial dysfunction, inflammation and pro-thrombotic effects leading to tissue ischemia $[5,6]$. This myocardial ischemia can cause angina, electrocardiogram (ECG) changes, and elevation of cardiac biomarkers $[1,7]$. 
For the accurate and timely diagnosis of myocardial injury, cardiac troponins (troponin) are the guidelinerecommended biomarker. When there is an elevation of troponin of $>99^{\text {th }}$ percentile of the upper reference level (URL), there is myocardial injury [8, 9]. If serial measurements of troponin reveal a variation of $>20 \%$ of a previous value in the presence of signs and symptoms of ischemia, then a diagnosis of myocardial infarction (MI) is made [10]. In more recent years, high-sensitivity troponin assays are more commonly being used in clinical practice, and thus improving the detection rates of myocardial injury [9, 11, 12]. However, with increasing minute levels of detected troponin, there are now concerns over the non-CAD specific etiology and possibly identifying adverse cardiovascular phenotype [13, 14]. Therefore, many studies have now suggested that for age, sex and comorbid conditions there should be specific $99^{\text {th }}$ percentile cutoffs for each troponin assay to diagnose myocardial injury [15-19].

Despite the high prevalence of hypertensive crisis and possible adverse cardiovascular outcomes among those with elevated troponin, the risk factors associated with myocardial injury, detectable troponin and changes in serial troponin levels are largely not known [7,20]. The aim of this study was to identify $99^{\text {th }}$ percentile levels for patients admitted with hypertensive crisis, among all patients and different phenotypes, as well as identify the important risk factors associated with troponin levels among these patients. We were particularly interested in the association of troponin levels and body mass index (BMI), as this has never been explored among patients with hypertensive crisis, and because of the known "obesity paradox".

\section{Materials And Methods Methods}

A retrospective cohort study was designed based on emergency room visits at Cabell Huntington Hospital / Marshall University Medical Center. Data from the electronic medical record (EMR) was extracted for the time period from October 2016 to October 2018. International Classification of Diseases, $10^{\text {th }}$ revision, Clinical Modification (ICD-10-CM) codes were used for the identification of the qualifying diagnoses. The cohort included all patients $\geqslant 18$ years old with the diagnosis of hypertensive urgency, hypertensive emergency or unspecified hypertensive crisis, by utilizing the following primary diagnostic codes: I16.0, I16.1, and I16.9, respectively. Patients with missing laboratory values $(n=43)$ or those diagnosed with the acute coronary syndrome $(n=6)$ were excluded.

\section{Variables of Interest}

Covariates included baseline demographics: age, gender, race, BMI and smoking status; also comorbidities commonly associated with heart disease were included such as diabetes, hyperlipidemia, cerebrovascular accident, CAD, heart failure, chronic kidney disease (CKD), cerebrovascular accident (CVA) and peripheral vascular disease (PVD). ICD-10-CM codes were used to identify these comorbidities. Other selected variables were: initial creatinine levels, an average of first three systolic and diastolic blood pressures (SBP and DBP), as well as prior outpatient medications including calcium channel blockers, beta-blockers, diuretics, aspirin, angiotensin-converting enzyme inhibitors (ACEI), angiotensin receptor blockers (ARB) and statins.

\section{Cardiac troponin assay}

The troponin assay used during the study period was Siemens Dimension Vista ${ }^{\circledR}$ System (Munich, Germany); limit of detection of $0.015 \mathrm{ng} / \mathrm{ml}$, coefficient of variation (CV) $10 \%$ is $0.04 \mathrm{ng} / \mathrm{ml}$ and the $99^{\text {th }}$ percentile of $\mathrm{URL}$ is $\geqslant 0.045 \mathrm{ng} / \mathrm{ml}[21]$.

\section{Outcomes}

The $99^{\text {th }}$ percentile was identified for the whole cohort and by age, gender, BMI, CKD, and race. The primary outcome was myocardial injury (defined as $>99^{\text {th }}$ percentile of the URL as per the Fourth Universal Definition of Myocardial Infarction [10]. We also explored the risk factors associated with 1) detectable troponin ( $>0.015 \mathrm{ng} / \mathrm{ml})$ and 2 ) changes in serial troponin levels.

\section{Statistical analysis}

The data are presented as proportions, means ( \pm standard deviation), and in case of non-normal distribution as median with inter-quartile range (IQR). Comparisons were made using the t-test for normally distributed continuous variables, Mann-Whitney U-test for non-normally distributed continuous variables, Fisher exact test for categorical variables with any field including less than six patients, and chi-square test for the other categorical variables. The Kolmogorov-Smirnov test was used to test for normality. We tested the associations between all covariates and the three outcomes with troponin levels 1 ) initial $>99^{\text {th }}$ percentile of URL; 2) initial detectable troponin; 3) change in serial troponin. Those covariates significantly associated with the outcome in bivariate analyses (with $\mathrm{p}<0.10$ ) were used to build a full adjusted model. Odds ratio (OR) were calculated with a $95 \%$ confidence interval (CI), comparing the significant risk factors associated with the outcome, using binary logistic regression analysis. We also tested for interactions between our main 
effect variable (BMI) and the subgroups (age, gender and smoking status) using models adjusted for variables similar to those included in the model. A two-sided $p$-value of $\leqslant 0.05$ was considered significant for main effects and for interactions.

To test for best fitting model between troponin levels and BMI, scatter plots and curve estimation analyses (tested for linear, logarithmic, inverse, compound, power, S, exponential, growth, logistic) were performed. Quadratic and cubic curves were not included, because scatter plots and the Loess curve did not reveal such an association and were clinically not expected. $\mathrm{R}^{2}$ was calculated to assess the performance of the model. Because sensitive cardiac troponins had a non-normal distribution, natural log transformation was performed on values in $\mathrm{ng} / \mathrm{ml}$ to avoid negative values. Data were analyzed using Statistical Package for Social Sciences (SPSS) software (version 24, IBM Inc, Armonk, USA).

\section{Results}

A total of 467 patients presenting to the emergency department (ED) with a hypertensive emergency, hypertensive urgency or unspecified hypertensive crisis were included in the study. The median initial troponin value of all patients was $\leqslant 0.015 \mathrm{ng} / \mathrm{ml}$ (i.e., non-detectable), while the $90^{\text {th }}, 95^{\text {th }}$, and $99^{\text {th }}$ percentiles were $0.071 \mathrm{ng} / \mathrm{ml}, 0.137 \mathrm{ng} / \mathrm{ml}$ and $0.433 \mathrm{ng} / \mathrm{ml}$ respectively (Figure 1 and Table 1 ). The median, $90^{\text {th }}, 95^{\text {th }}$ and $99^{\text {th }}$ percentiles of all patients and subgroups are also shown in Table 1 . The $99^{\text {th }}$ percentiles were higher among those who were older, female, BMI $<30 \mathrm{~kg} / \mathrm{m}^{2}$ and CKD. There were not enough African American patients $(n=67)$ to generate $99^{\text {th }}$ percentile; however, the $90^{\text {th }}$ and $95^{\text {th }}$ percentiles were higher in African Americans than among Caucasians.

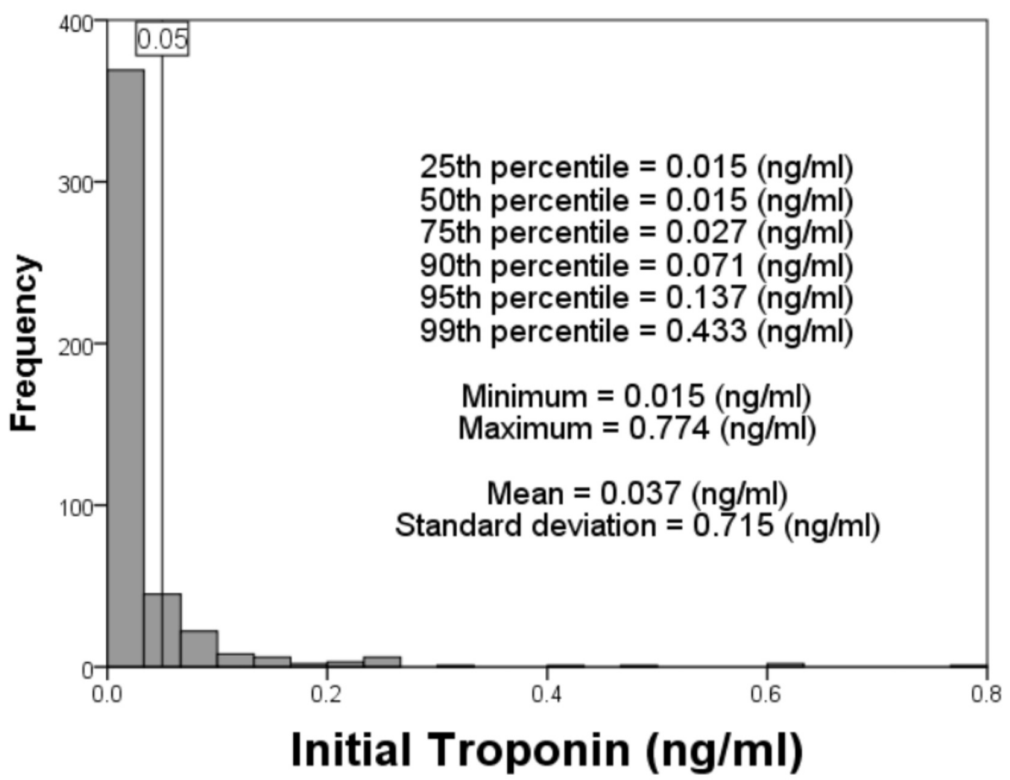

FIGURE 1: Distribution of initial troponin among all hypertensive crisis patients 


\section{Cureus}

\begin{tabular}{|c|c|c|c|c|c|}
\hline & N (\%) & $50^{\text {th }}$ & $90^{\text {th }}$ & $95^{\text {th }}$ & $99^{\text {th }}$ \\
\hline All patients & 467 & 0.015 & 0.071 & 0.137 & 0.433 \\
\hline Age $\leq 61$ year & 234 (50\%) & 0.015 & 0.089 & 0.150 & 0.256 \\
\hline Age $>61$ year & 233 (50\%) & 0.015 & 0.060 & 0.103 & 0.612 \\
\hline Male & 191 (41\%) & 0.015 & 0.090 & 0.155 & 0.257 \\
\hline Female & 276 (59\%) & 0.015 & 0.061 & 0.112 & 0.611 \\
\hline $\mathrm{BMI} \geq 30 \mathrm{~kg} / \mathrm{m}^{2}$ & 229 (49\%) & 0.015 & 0.057 & 0.095 & 0.295 \\
\hline $\mathrm{BMI}<30 \mathrm{~kg} / \mathrm{m}^{2}$ & $238(51 \%)$ & 0.015 & 0.090 & 0.149 & 0.567 \\
\hline Without CKD & 291 (82\%) & 0.015 & 0.051 & 0.088 & 0.288 \\
\hline CKD & 176 (38\%) & 0.017 & 0.118 & 0.186 & 0.561 \\
\hline Caucasian & 396 (85\%) & 0.015 & 0.068 & 0.122 & 0.500 \\
\hline African American & $67(14 \%)$ & 0.015 & 0.104 & 0.180 & - \\
\hline
\end{tabular}

TABLE 1: Percentiles of initial troponin among all hypertensive crisis patients and subgroups CKD - chronic kidney disease; BMI - body mass index

\section{Myocardial injury (troponin $>99^{\text {th }}$ percentile)}

The baseline characteristics and their association with myocardial injury are shown in Table 2. A total of $15 \%$ were found to have a myocardial injury. After entering all the covariates that were found significant in Table 2, the binary logistic regressions showed patients with BMI $<30 \mathrm{~kg} / \mathrm{m}^{2}$, those with a prior diagnosis of heart failure and those with use of aspirin on admission, were significantly associated with higher odds of myocardial injury. Patients with a history of CAD showed a non-significant trend towards myocardial injury (Figure 2). 


\section{Cureus}

All patients $n=467$

At time of emergency department visit

Age Per year

Age $>61$ year

Male gender

Caucasian

BMI Per $\mathrm{kg} / \mathrm{m}^{2}$

$\mathrm{BMI} \geq 30 \mathrm{~kg} / \mathrm{m}^{2}$

Mean arterial pressure $(\mathrm{mmHg})$

Creatinine (mg/dl)

Prior history

Diabetes

Hypertension

Hyperlipidemia

Coronary artery disease

Cerebrovascular accident

Chronic kidney disease

Peripheral vascular disease

Heart failure

Smoking status

Ex-smoker

Never-smoker

Outpatient medications

Aspirin

$\beta$-blockers

Diuretics

ACEI or ARB

Calcium channel blockers

Statin
Troponin $>99^{\text {th }}$ percentile

No; n=397 (85)

Yes; $\mathrm{n}=70$ (15)

p-value

$62[51-71]$

204 (51)

59 [52 - 71]

0.309

$29(41)$

0.124

155 (39)

$36(51)$

0.052

340 (86)

$56(80)$

0.225

$30[25-36]$

28 [23 - 34]

0.028

204 (51)

25 (36)

0.016

138 [127 - 153]

$1.06[0.85-1.40]$

138 [123 - 151]

0.308

$1.35[1.01-2.26]$

$<0.001$

203 (51)

$36(51)$

0.964

382 (96)

267 (67)

166 (42)

144 (36)

135 (34)

$115(29)$

97 (24)

137 (35)

101 (25)

$159(40)$

69 (99)

0.319

0.627

$<0.001$

$45(64)$

0.551

$<0.001$

0.107

$<0.001$

$44(63)$

25 (36)

20 (29)

0.776

$25(36)$

79 (20)

23 (33)

0.016

139 (35)

30 (43)

0.208

111 (28)

22 (31)

0.553

147 (37)

25 (36)

0.834

103 (26)

18 (26)

0.968

97 (24)

$17(24)$

0.979

TABLE 2: Baseline characteristics and myocardial injury (troponin > 99th percentile)

BMI - body mass index; ACEI - angiotensin-converting enzyme inhibitors; ARB - angiotensin receptor blockers 


\section{Cureus}

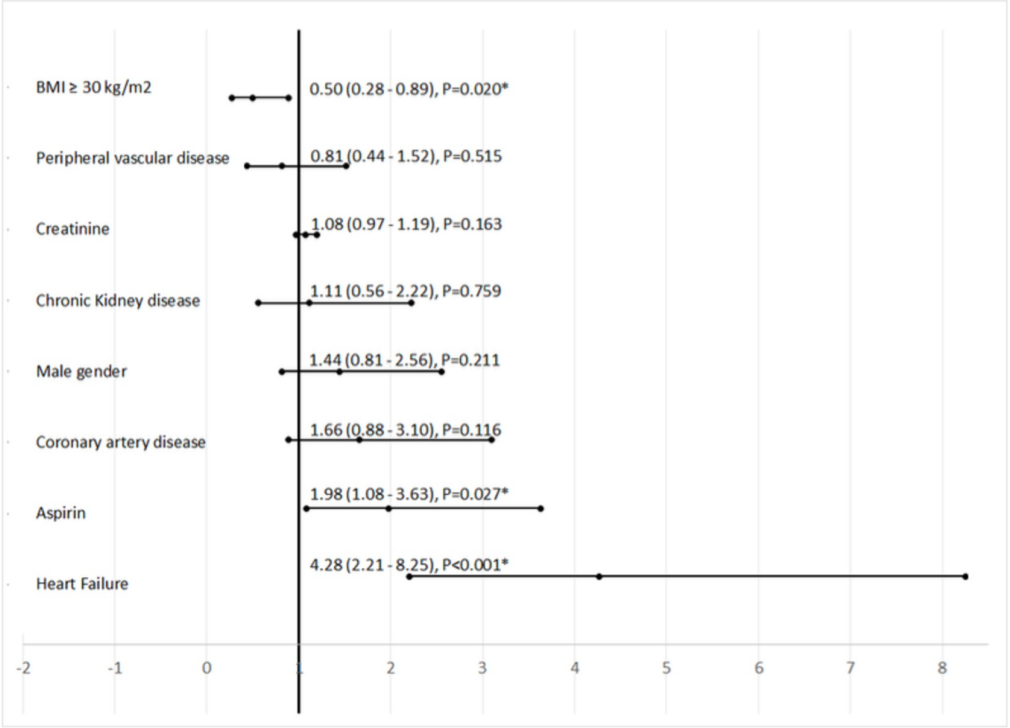

FIGURE 2: Predictors for myocardial injury from binary logistic regression among those found significant in Table 2

$\mathrm{BMI}$ - body mass index

\section{Detectable troponin (troponin $>0.015 \mathbf{n g} / \mathrm{ml}$ )}

A total of 166 (35\%) patients were found to have detectable troponin (Table 3). In the fully adjusted binary regression model, the covariates that were significantly associated with detectable troponin were: $\mathrm{BMI}<30$ $\mathrm{kg} / \mathrm{m}^{2}$, age $\leqslant 61$ years, elevated creatinine, and prior diagnosis of heart failure. Non-Caucasians and prior use of beta-blocker showed a non-significant trend towards detectable troponin (Figure 3). 


\section{Cureus}

All patients $n=467$

At time of emergency department visit

\begin{tabular}{|c|c|c|c|c|c|}
\hline \multicolumn{2}{|l|}{ Age per year } & $61[51-71]$ & $62[51-71]$ & $60[50-70]$ & 0.168 \\
\hline \multicolumn{2}{|l|}{ Age $>61$ year } & $233(50)$ & $161(54)$ & $72(43)$ & 0.036 \\
\hline \multicolumn{2}{|l|}{ Male gender } & $276(59)$ & $112(37)$ & $79(48)$ & 0.029 \\
\hline \multicolumn{2}{|l|}{ Caucasian } & $396(85)$ & $263(87)$ & $133(80)$ & 0.037 \\
\hline \multicolumn{2}{|l|}{ BMI per $\mathrm{kg} / \mathrm{m}^{2}$} & $30[25-36]$ & $30[25-37]$ & 28 [25-35] & 0.155 \\
\hline \multicolumn{2}{|l|}{$\mathrm{BMI} \geq 30 \mathrm{~kg} / \mathrm{m}^{2}$} & $229(49)$ & $159(53)$ & 70 (42) & 0.027 \\
\hline \multicolumn{2}{|c|}{ Mean arterial pressure $(\mathrm{mmHg})$} & 138 [126 - 153] & $137[126-151]$ & 140 [126 - 157] & 0.341 \\
\hline \multicolumn{2}{|c|}{ Creatinine (mg/dl) } & $1.06[0.86-1.54]$ & $0.98[0.81-1.22]$ & $1.33[1.02-2.31]$ & $<0.001$ \\
\hline \multicolumn{6}{|l|}{ Prior history } \\
\hline \multicolumn{2}{|l|}{ Diabetes } & $239(51)$ & $151(50)$ & $88(53)$ & 0.556 \\
\hline \multicolumn{2}{|l|}{ Hypertension } & 451 (97) & $288(96)$ & $163(98)$ & 0.153 \\
\hline \multicolumn{2}{|l|}{ Hyperlipidemia } & $312(67)$ & $202(67)$ & $110(66)$ & 0.853 \\
\hline \multicolumn{2}{|c|}{ Coronary artery disease } & 211 (45) & $119(40)$ & $92(55)$ & 0.001 \\
\hline \multicolumn{2}{|c|}{ Cerebrovascular accident } & $172(37)$ & $110(37)$ & $62(37)$ & 0.863 \\
\hline \multicolumn{2}{|c|}{ Chronic kidney disease } & $176(38)$ & $85(28)$ & $91(55)$ & $<0.001$ \\
\hline \multicolumn{2}{|c|}{ Peripheral vascular disease } & $142(30)$ & $77(26)$ & $65(39)$ & 0.002 \\
\hline \multicolumn{2}{|l|}{ Heart failure } & $141(30)$ & 57 (19) & $84(51)$ & $<0.001$ \\
\hline \multirow{3}{*}{ Smoking status } & Active smoker & $162(35)$ & $99(33)$ & $63(38)$ & \\
\hline & Ex-smoker & $121(26)$ & 77 (26) & $44(27)$ & 0.407 \\
\hline & Never-smoker & $184(39)$ & $125(42)$ & $59(36)$ & \\
\hline \multicolumn{6}{|c|}{ Prior outpatient medications } \\
\hline \multicolumn{2}{|l|}{ Aspirin } & $102(22)$ & $62(21)$ & $40(24)$ & 0.381 \\
\hline \multicolumn{2}{|l|}{$\beta$-blockers } & $169(36)$ & $96(32)$ & 73 (44) & 0.009 \\
\hline \multicolumn{2}{|l|}{ Diuretics } & $133(29)$ & $86(29)$ & $47(28)$ & 0.953 \\
\hline \multicolumn{2}{|l|}{ ACEl or ARB } & $172(37)$ & $110(37)$ & $62(37)$ & 0.863 \\
\hline \multicolumn{2}{|c|}{ Calcium channel blockers } & $121(26)$ & $72(24)$ & $49(30)$ & 0.186 \\
\hline \multicolumn{2}{|l|}{ Statin } & 114 (24) & 75 (25) & 39 (24) & 0.732 \\
\hline
\end{tabular}

\section{TABLE 3: Baseline characteristics and detectable troponin (troponin $>0.015 \mathrm{ng} / \mathrm{ml}$ )}




\section{Cureus}

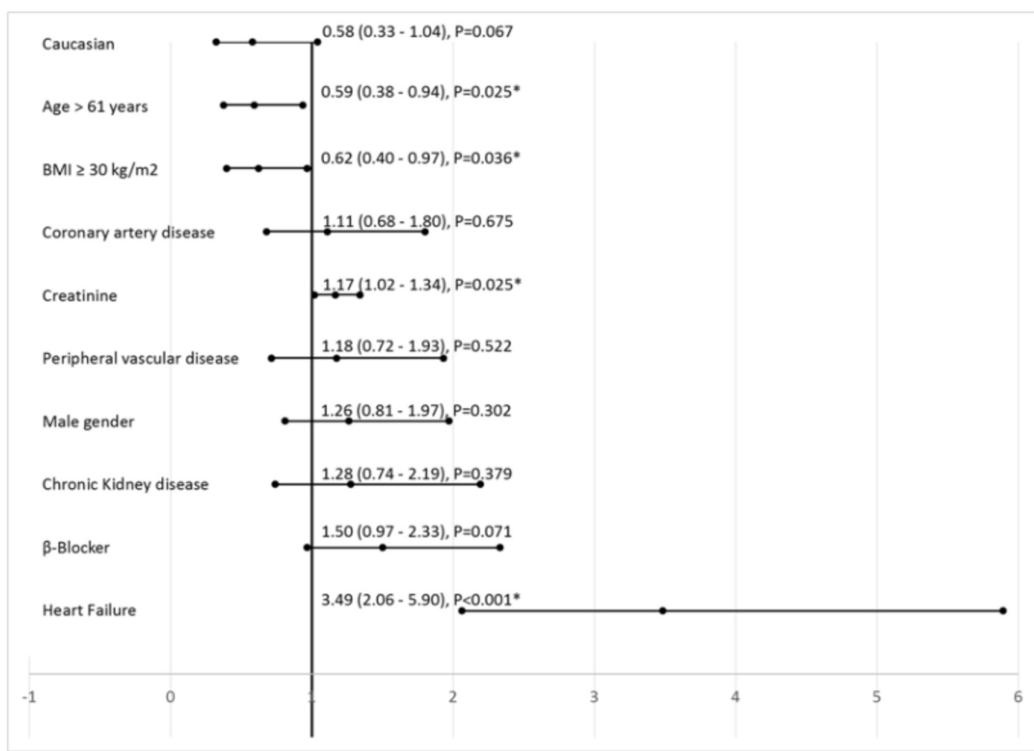

FIGURE 3: Predictors for detectable troponin from binary logistic regression among those found significant in Table 3

$\mathrm{BMI}$ - body mass index

\section{BMI and troponin levels}

About half of our cohort were defined as obese (BMI $\geqslant 30 \mathrm{~kg} / \mathrm{m} 2)$. In obese patients ( $\mathrm{n}=229,49 \%)$, the $95^{\text {th }}$ and $99^{\text {th }}$ percentile of the initial troponin values were $0.095 \mathrm{ng} / \mathrm{ml}$ and $0.295 \mathrm{ng} / \mathrm{ml}$, respectively, whereas that among non-obese patients were $0.149 \mathrm{ng} / \mathrm{ml}$ and $0.567 \mathrm{ng} / \mathrm{ml}$, respectively. Lower BMI had a significantly higher association with myocardial injury, detectable troponin, and positive change in serial troponin. It also had a significant negative linear relationship with initial troponin levels. Among different models applied to the association between log-transformed high-sensitivity cardiac troponin and BMI, inverse function achieved the highest significant $\mathrm{R}^{2}\left(\mathrm{R}^{2}=0.019\right.$, constant $\left.=-4.176, \mathrm{~b} 1=11.510, \mathrm{p}=0.003\right)$ (Figure 4).

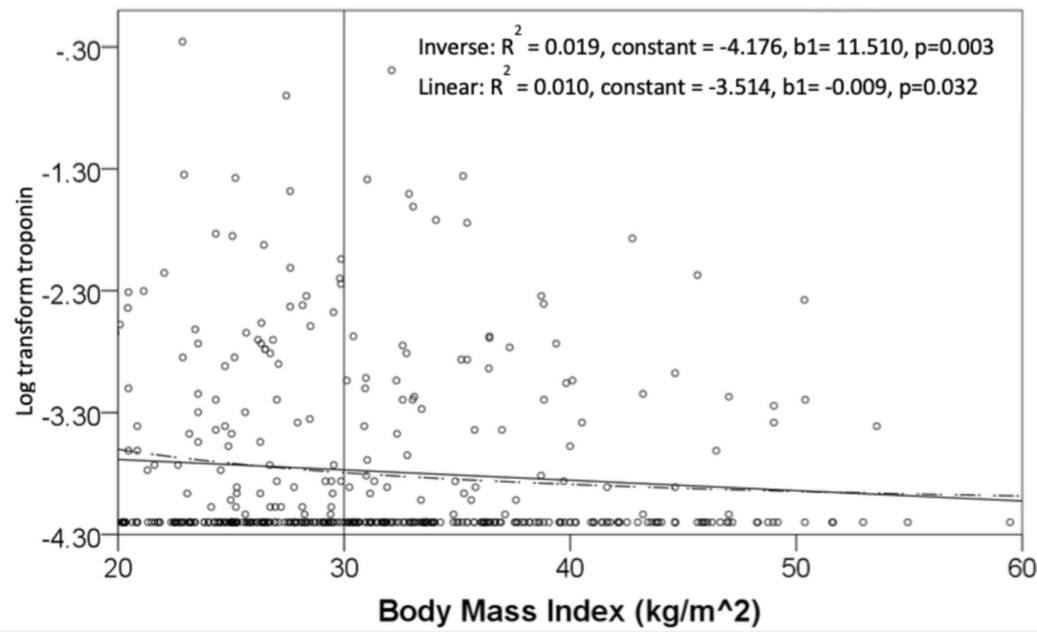

FIGURE 4: Relationship of initial log transform troponin levels and body mass index in $\mathrm{kg} / \mathrm{m} 2$

\section{Serial troponin levels}

Among all patients, 135 (29\%) had a positive change in serial troponin levels compared to their initial troponin (Table 4). Patients with BMI $<30 \mathrm{~kg} / \mathrm{m}^{2}$, non-Caucasians, prior diagnosis of heart failure, and prior 


\section{Cureus}

CAD were significantly associated with an increase in troponin levels from baseline. Prior use of beta-blocker showed a non-significant trend towards change in troponin (Figure 5). The majority of patients who did not have a change in serial troponin $(\mathrm{n}=332,71 \%)$, also did not have initial troponin $>99^{\text {th }}$ percentile $(95 \%)$ (Table 5). Only four patients ( $0.9 \%$ of the whole cohort) had a positive change in relative troponin in the range of $\geqslant 20 \%$ from the baseline troponin levels.

\begin{tabular}{|c|c|c|c|}
\hline \multirow{2}{*}{ Initial troponin } & \multicolumn{2}{|c|}{ Serial troponin positive } & \multirow{2}{*}{ p-value } \\
\hline & No; $n=332(71)$ & Yes; n=135 (29) & \\
\hline Not detected & $263(79)$ & $0(0)$ & \multirow{2}{*}{$<0.001$} \\
\hline Detected & $69(21)$ & $135(100)$ & \\
\hline$\leq 99^{\text {th }}$ percentile & $315(95)$ & $82(61)$ & \multirow{2}{*}{$<0.001$} \\
\hline$>99^{\text {th }}$ percentile & $17(5)$ & $53(39)$ & \\
\hline
\end{tabular}

TABLE 4: The proportion of patients with and without an increase in serial troponin levels by the initial troponin detected and $>99$ th percentile

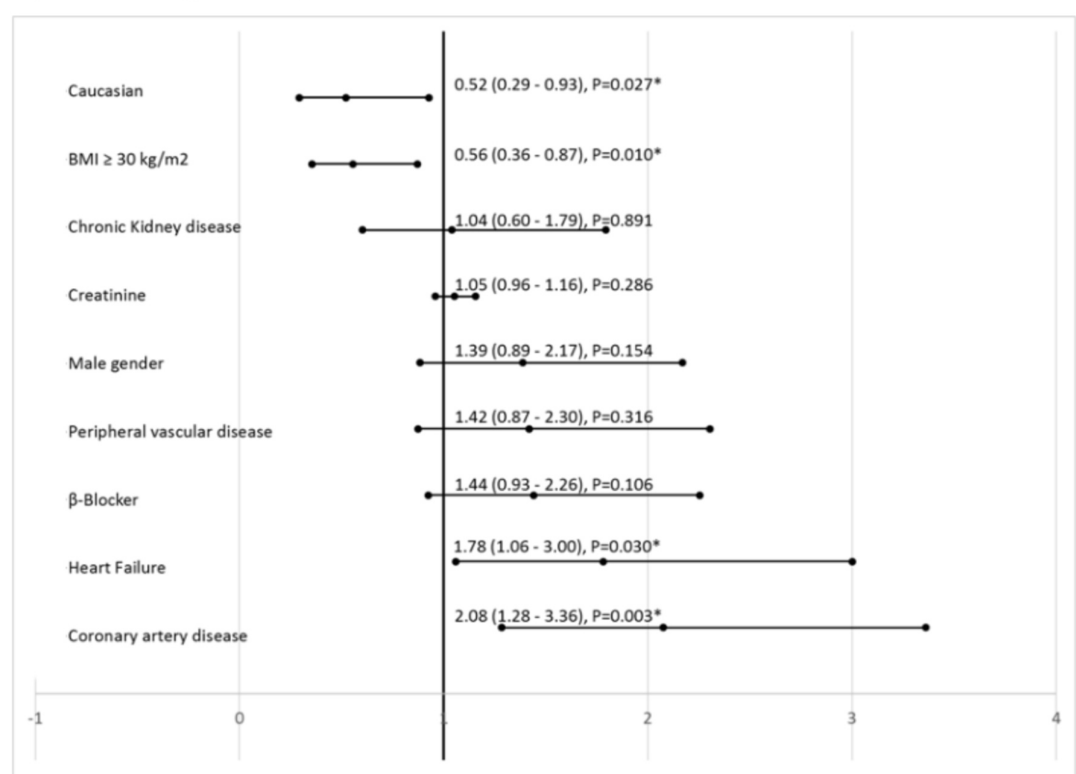

FIGURE 5: Predictors for positive serial troponin from binary logistic regression

BMI - body mass index 


\section{Cureus}

\begin{tabular}{|c|c|c|c|}
\hline \multirow{2}{*}{ Initial troponin } & \multicolumn{2}{|c|}{ Serial troponin positive } & \multirow{2}{*}{ p-value } \\
\hline & No; $n=332$ (71) & Yes; n=135 (29) & \\
\hline Not detected & $263(79)$ & $0(0)$ & \multirow{2}{*}{$<0.001$} \\
\hline Detected & $69(21)$ & $135(100)$ & \\
\hline$\leq 99^{\text {th }}$ percentile & $315(95)$ & $82(61)$ & \multirow{2}{*}{$<0.001$} \\
\hline$>99^{\text {th }}$ percentile & $17(5)$ & $53(39)$ & \\
\hline
\end{tabular}

TABLE 5: The proportion of patients with and without an increase in serial troponin levels by the initial troponin detected and $>99$ th percentile

There was also evidence of effect modification by age and by gender, where the association between low BMI and myocardial injury (initial troponin $>99^{\text {th }}$ percentile) was stronger in older age group (interaction $\mathrm{p}$ value $=0.003$ ) and females (interaction $\mathrm{p}$-value $=0.017$ ). There was no effect modification by the subgroups between the association of BMI and detectable troponin and positive serial troponin levels (Table 6).

\begin{tabular}{|c|c|c|c|c|c|c|}
\hline & \multicolumn{2}{|l|}{ Myocardial injury } & \multicolumn{2}{|c|}{ Detectable troponin } & \multicolumn{2}{|c|}{ Positive serial troponin levels } \\
\hline & $\begin{array}{l}\text { Odds ratio }(95 \% \\
\mathrm{Cl})\end{array}$ & $\begin{array}{l}\text { Interaction p- } \\
\text { value }\end{array}$ & $\begin{array}{l}\text { Odds ratio }(95 \% \\
\mathrm{Cl})\end{array}$ & $\begin{array}{l}\text { Interaction p- } \\
\text { value }\end{array}$ & $\begin{array}{l}\text { Odds ratio }(95 \% \\
\mathrm{Cl})\end{array}$ & $\begin{array}{l}\text { Interaction } \mathrm{p} \text { - } \\
\text { value }\end{array}$ \\
\hline $\begin{array}{l}\text { Age } \leq 61 \\
\text { years }\end{array}$ & $0.98(0.44,2.15)$ & \multirow{2}{*}{0.003} & $0.96(0.48,1.91)$ & \multirow{2}{*}{0.315} & $0.78(0.39,1.55)$ & \multirow{2}{*}{0.981} \\
\hline $\begin{array}{l}\text { Age }>61 \\
\text { years }\end{array}$ & $0.13(0.04,0.39)$ & & $0.49(0.26,0.93)$ & & $0.44(0.23,0.84)$ & \\
\hline Female & $0.23(0.09,0.56)$ & \multirow{2}{*}{0.017} & $1.09(0.53,2.25)$ & \multirow{2}{*}{0.158} & $0.62(0.29,1.30)$ & \multirow{2}{*}{0.843} \\
\hline Male & $1.01(0.45,2.29)$ & & $0.42(0.23,0.76)$ & & $0.50(0.28,0.91)$ & \\
\hline $\begin{array}{l}\text { Active } \\
\text { smoker }\end{array}$ & $0.61(0.19,1.98)$ & \multirow{3}{*}{0.792} & $0.50(0.22,1.15)$ & \multirow{3}{*}{0.472} & $0.66(0.28,1.54)$ & \multirow{3}{*}{0.421} \\
\hline Ex-smoker & $0.27(0.07,1.04)$ & & $1.10(0.46,2.62)$ & & $0.42(0.15,1.21)$ & \\
\hline $\begin{array}{l}\text { Never- } \\
\text { smoker }\end{array}$ & $0.40(0.15,1.10)$ & & $0.44(0.34,1.53)$ & & $0.67(0.32,1.38)$ & \\
\hline
\end{tabular}

TABLE 6: Association between body mass index and myocardial injury, detectable troponin and serial troponin changes in subgroups

\section{Discussion}

This is the first study to establish $99^{\text {th }}$ percentiles of troponin levels among patients with hypertensive crises and subgroups (age, gender, BMI, CKD, and race). We identified the significant risk factors that predict myocardial injury, detectable troponin, and increase in serial troponin levels among hypertensive crisis patients. There are several major findings and important clinical implications of the study.

First, in our cohort, $15 \%$ had troponin $>99^{\text {th }}$ percentile of URL and the $99^{\text {th }}$ percentile of troponin for all patients was $0.433 \mathrm{ng} / \mathrm{ml}$ (almost 10 times higher of that recommended by the manufacturer to identify myocardial injury $[0.045 \mathrm{ng} / \mathrm{ml}])$. However, only $<1 \%$ had a relative change in serial troponin levels of greater than $20 \%$, suggesting the majority of hypertensive crisis patients will be categorized as chronic myocardial injury. This provides evidence that serial troponin levels can potentially, more reliably,

differentiate hypertensive crisis from ACS patients, rather than one-time troponin level. The second major finding is that patients with lower BMI, prior CHF and prior use of aspirin were the only factors significantly associated with myocardial injury. Interestingly, we also found the negative association between BMI and the myocardial injury was significantly stronger among female and older patient groups. Third, low BMI and 
prior diagnoses of CHF were the only variables consistently associated with all outcomes (myocardial injury, detectable troponin, and increase in serial troponin levels).

Other minor findings are 1) there was no association with presenting blood pressure (SBP, DBP, mean arterial blood pressure, pulse pressure) and troponin levels among all patients and in subgroups (data not shown); 2) elevated creatinine contributes to troponin being detectable but not with myocardial injury; 3 ) younger compared to older age group patients had higher association with detectable troponin (not with myocardial injury), and overall troponin levels had a significant negative linear relationship with age; 4) no significant difference between troponin levels and gender after adjusting to significant covariates; 5) nonCaucasians were more likely to have detectable troponin and increase in serial troponin, but not myocardial injury.

\section{Body Mass Index}

In our study, the $99^{\text {th }}$ percentile of the troponin level for patients with obesity was significantly lower than non-obese patients. Patients with BMI $<30 \mathrm{~kg} / \mathrm{m} 2$ were significantly associated with higher odds of myocardial injury, detectable troponin, and an increase in serial troponin levels. After adjusting for significant covariates, there was a negative linear and inverse relationship between BMI and troponin level. Although it is well known that obesity is an independent risk factor for developing heart disease, there are several large databases that have demonstrated that obese patients have a better short and long term prognosis compared to normal/low weight, among those with CAD and heart failure patients; commonly referred to as the "obesity paradox" [22-28]. We for the first time also found a similar obesity paradox phenomenon among hypertensive crisis patients. The mechanisms by which normal BMI patients have a higher prevalence of detectable and elevated troponin is not clear. Smoking is known to have a strong independent inverse association with adiposity and a possible explanation for the paradox [29]. However, we did not find any interaction effect of smoking status on the association between BMI and troponin levels. Other possible mechanisms to this phenomenon could be that despite obesity being characterized by increased circulating blood volume, systemic vascular resistance and left ventricular mass (which contribute to development of hypertension) obese patients have 1) lower baseline levels of the renin-angiotensin system and attenuated neurohormonal responses to stress; 2) increased nutritional and metabolic reserves; 3) might better tolerate cardio-protective medications because of elevated blood pressures [28, 30]. Lastly, this obesity paradox could be erroneous due to the possible higher undiagnosed systemic conditions or more severe illnesses and unintentional weight loss among lean patients. Interestingly, we found that the obesity paradox to be stronger among an older group and female patients, a finding which is supported by another study which showed obesity was associated with lower in-hospital mortality in patients $\geqslant 70$ years with myocardial infarction, with a more pronounced paradox in women. Similar female gender-specific and older age-specific obesity paradox has been found in other studies [28].

\section{Other clinical variables and implications}

Even though the $99^{\text {th }}$ percentile was lower among patients $<61$ years, lower creatinine and CKD, after adjusting for significant covariates, patients $<61$ years and elevated creatinine were independently associated with detectable troponin, but not with myocardial injury and serial troponin levels. There was a strong significant negative linear relationship between initial troponin and age and creatinine. This is in contrast to previous studies that have suggested a higher URL for older patients group. The mechanism for the negative relationship between troponin and age among these patients is not known. A possible explanation could be that secondary hypertension is more common among the younger patient group, and manifest different phenotype, etiology, and mechanisms of troponin leak compared to older counterparts. Another possible explanation for such a finding could be that younger patients tend to be less compliant with their medications leading to more extreme elevations in blood pressure and thus causing more myocardial injury. There is also less awareness, treatment, and control of hypertension in younger adults, and this adverse outcome is possibly reflected by higher troponin levels among our study patients.

In our study, apart from BMI, those patients with a prior diagnosis of CHF, was the only other covariate, that had significantly higher odds of having a myocardial injury, a detectable troponin, and serial troponin levels. This is consistent with prior studies showing that most patients with stable chronic heart failure have detectable troponin, even when the heart failure is chronic and the patient is euvolemic. Patients with prior CAD had significantly higher odds of having detectable troponin levels and a non-significant trend towards myocardial injury, as they are more likely to have a myocardial injury because of increased myocardial oxygen demand and limited supply [10].

\section{Limitations}

Our study was single-center, retrospective and our data set was limited to the use of ICD-10-CM data (from October 2015). Based on our data, we cannot investigate the different causes of troponin elevation. We could not identify other acute conditions (such as hypoxia, pulmonary embolism, anemia, etc), that are known to cause troponin elevation and may coexist at the time of admission. Despite this is the first study, we were limited by sample size. There are several other clinical tools (such as history, electrocardiogram, echocardiogram, etc) and methods of obesity measurement (such as body surface area, waist circumference, 
lean body mass, etc) which were unavailable and could potentially better explain troponin levels and warrants further research.

\section{Conclusions}

About one-third of patients with the hypertensive crisis have detectable troponin. Still, among these patients, less than half have troponin levels consistent with myocardial injury, and the majority of these patients have minimal changes in serial troponin. Low BMI, prior CHF, and use of aspirin are independently associated with myocardial injury among these patients. Low BMI is significantly associated with higher initial and serial troponins. The significant negative association between BMI and the myocardial injury was stronger among female and older patient groups. These observations enhance our knowledge of pathophysiology, risk factors, and the clinical importance associated with baseline and serial troponin levels among hypertensive crisis patients.

\section{Additional Information \\ Disclosures}

Human subjects: Consent was obtained by all participants in this study. Marshall University IRB issued approval 1216562-2. Approved by the Marshall University IRB. Animal subjects: All authors have confirmed that this study did not involve animal subjects or tissue. Conflicts of interest: In compliance with the ICMJE uniform disclosure form, all authors declare the following: Payment/services info: All authors have declared that no financial support was received from any organization for the submitted work. Financial relationships: All authors have declared that they have no financial relationships at present or within the previous three years with any organizations that might have an interest in the submitted work. Other relationships: All authors have declared that there are no other relationships or activities that could appear to have influenced the submitted work.

\section{References}

1. Papadopoulos DP, Sanidas EA, Viniou NA, et al.: Cardiovascular hypertensive emergencies. Curr Hypertens Rep. 2015, 17:5. 10.1007/s11906-014-0515-Z

2. Whelton PK, Carey RM, Aronow WS, et al.: 2017 ACC/AHA/AAPA/ABC/ACPM/AGS/APhA/ASH/ASPC/NMA/PCNA guideline for the prevention, detection, evaluation, and management of high blood pressure in adults: a report of the American College of Cardiology/American Heart Association Task Force on clinical practice guidelines. J Am Coll Cardiol. 2017, 12:238. 10.1016/j.jash.2018.01.004

3. Fihn SD, Blankenship JC, Alexander KP, et al.: 2014 ACC/AHA/AATS/PCNA/SCAI/STS focused update of the guideline for the diagnosis and management of patients with stable ischemic heart disease: a report of the American College of Cardiology/American Heart Association Task Force on Practice Guidelines, and the American Association for Thoracic Surgery, Preventive Cardiovascular Nurses Association, Society for Cardiovascular Angiography and Interventions, and Society of Thoracic Surgeons. J Am Coll Cardiol. 2014, 64:1929-1949. 10.1016/j.jacc.2014.07.017

4. Chapman AR, Shah ASV, Lee KK, et al.: Long-term outcomes in patients with type 2 myocardial infarction and myocardial injury. Circulation. 2018, 137:1236-1245. 10.1161/CIRCULATIONAHA.117.031806

5. van den Born BJ, Lowenberg EC, van der Hoeven NV, et al.: Endothelial dysfunction, platelet activation, thrombogenesis and fibrinolysis in patients with hypertensive crisis. J Hypertens. 2011, 29:922-927. 10.1097/HJH.0b013e328345023d

6. Derhaschnig U, Testori C, Riedmueller E, Aschauer S, Wolzt M, Jilma B: Hypertensive emergencies are associated with elevated markers of inflammation, coagulation, platelet activation and fibrinolysis. J Hum Hypertens. 2013, 27:368-373. 10.1038/jhh.2012.53

7. Pattanshetty DJ, Bhat PK, Aneja A, Pillai DP: Elevated troponin predicts long-term adverse cardiovascular outcomes in hypertensive crisis: a retrospective study. J Hypertens. 2012, 30:2410-2415. 10.1097/HJH.0b013e3283599b4f

8. Thygesen K, Alpert JS, Jaffe AS, et al.: Third universal definition of myocardial infarction. Eur Heart J. 2012, 33:2551-2567. 10.1161/CIR.0b013e31826e1058

9. Thygesen K, Mair J, Giannitsis E, et al.: How to use high-sensitivity cardiac troponins in acute cardiac care . Eur Heart J. 2012, 33:2252-2257. 10.1093/eurheartj/ehs154

10. Thygesen K, Alpert JS, Jaffe AS, et al.: Fourth universal definition of myocardial infarction (2018). Eur Heart J. 2019, 40: 237-269. 10.1093/eurheartj/ehy462

11. Thygesen K, Mair J, Katus H, et al.: Recommendations for the use of cardiac troponin measurement in acute cardiac care. Eur Heart J. 2010, 31:2197-2204. 10.1093/eurheartj/ehq251

12. Schmid J, Liesinger L, Birner-Gruenberger R, et al.: Elevated cardiac troponin $\mathrm{T}$ in patients with skeletal myopathies. J Am Coll Cardiol. 2018, 71:1540-1549. 10.1016/j.jacc.2018.01.070

13. Wallace TW, Abdullah SM, Drazner MH, et al.: Prevalence and determinants of troponin T elevation in the general population. Circulation. 2006, 113:1958-1965. 10.1161/CIRCULATIONAHA.105.609974

14. Collinson PO, Heung YM, Gaze D, et al.: Influence of population selection on the 99th percentile reference value for cardiac troponin assays. Clin Chem. 2012, 58:219-225. 10.1373/clinchem.2011.171082

15. Gore MO, Seliger SL, Defilippi CR, et al.: Age- and sex-dependent upper reference limits for the highsensitivity cardiac troponin T assay. J Am Coll Cardiol. 2014, 63:1441-1448. 10.1016/j.jacc.2013.12.032

16. Tate JR, Ferguson W, Bais R, Kostner K, Marwick T, Carter A: The determination of the 99th centile level for troponin assays in an Australian reference population. Ann Clin Biochem. 2008, 45:275-288.

10.1258/acb.2007.007185 
17. Jaffe AS, Jaffe HA: Use of high-sensitivity cardiac troponin in patients with chronic comorbidities: moving from theory to practice. J Am Coll Cardiol. 2018, 72:1138-1140. 10.1016/j.jacc.2018.06.052

18. Mueller-Hennessen M, Lindahl B, Giannitsis E, et al.: Diagnostic and prognostic implications using age- and gender-specific cut-offs for high-sensitivity cardiac troponin T - Sub-analysis from the TRAPID-AMI study. Int J Cardiol. 2016, 209:26-33. 10.1016/j.ijcard.2016.01.213

19. Mueller-Hennessen M, Giannitsis E: Do we need to consider age and gender for accurate diagnosis of myocardial infarction?. Diagnosis. 2016, 3:175-181. 10.1515/dx-2016-0023

20. Afonso L, Bandaru H, Rathod A, et al.: Prevalence, determinants, and clinical significance of cardiac troponin-I elevation in individuals admitted for a hypertensive emergency. J Clin Hypertens. 2011, 13:551556. 10.1111/j.1751-7176.2011.00476.x

21. Siemens Helthineers webiste. Accessed: 2019: https://www.healthcare.siemens.com.

22. Hubert HB, Feinleib M, McNamara PM, Castelli WP: Obesity as an independent risk factor for cardiovascular disease: a 26-year follow-up of participants in the Framingham Heart Study. Circulation. 1983, 67:968-977. 10.1161/01.CIR.67.5.968

23. Romero-Corral A, Montori VM, Somers VK, et al.: Association of bodyweight with total mortality and with cardiovascular events in coronary artery disease: a systematic review of cohort studies. Lancet. 2006, 368:666-678. 10.1016/S0140-6736(06)69251-9

24. Gruberg L, Weissman NJ, Waksman R, et al.: The impact of obesity on the short-term and long-term outcomes after percutaneous coronary intervention: the obesity paradox?. J Am Coll Cardiol. 2002, 39:578584. 10.1016/S0735-1097(01)01802-2

25. Nikolsky E, Stone GW, Grines CL, et al.: Impact of body mass index on outcomes after primary angioplasty in acute myocardial infarction. Am Heart J. 2006, 151:168-175. 10.1016/j.ahj.2005.03.024

26. Kang WY, Jeong MH, Ahn YK, et al.: Obesity paradox in Korean patients undergoing primary percutaneous coronary intervention in ST-segment elevation myocardial infarction. J Cardiol. 2010, 55:84-91. 10.1016/j.jjcc.2009.10.004

27. Kosuge M, Kimura K, Kojima S, et al.: Impact of body mass index on in-hospital outcomes after percutaneous coronary intervention for ST segment elevation acute myocardial infarction. Circ J. 2008, 72:521-525. 10.1253/circj.72.521

28. Oreopoulos A, Padwal R, Kalantar-Zadeh K, Fonarow GC, Norris CM, McAlister FA: Body mass index and mortality in heart failure: a meta-analysis. Am Heart J. 2008, 156:13-22. 10.1016/j.ahj.2008.02.014

29. Manson JE, Stampfer MJ, Hennekens CH, Willett WC: Body weight and longevity. A reassessment. JAMA. 1987, 257:353-358. 10.1001/jama.1987.03390030083026

30. Weber MA, Neutel JM, Smith DH: Contrasting clinical properties and exercise responses in obese and lean hypertensive patients. J Am Coll Cardiol. 2001, 37:169-174. 10.1016/S0735-1097(00)01103-7 